\title{
Bal oldali pneumothorax egy ritka EKG-megnyilvánulása: inferior STEMI és praecordialis Brugada-mintázat
}

\author{
Frigy Attila dr. - Kocsis Ildikó dr. - Fehérvári Lajos dr. - Máthé Lehel dr. \\ Marosvásárhelyi Orvosi és Gyógyszerészeti Egyetem (UMF Tg. Mureș), \\ IV. Belgyógyászati Tanszék, Marosvásárhely, Románia
}

\begin{abstract}
A nem coronariás eredetú ST-eleváció felismerése, okának tisztázása fontos a mindennapi gyakorlatban, elsősorban a felesleges diagnosztikus és terápiás eljárások elkerülése végett. Betegünk esetében egy viszonylag ritka ok, spontán, bal oldali feszülő pneumothorax állt az akutan kialakuló, komplex EKG-elváltozások hátterében - alsó fali infarktust utánzó ST-eleváció társulása l-es típusú Brugada-mintázattal ( $\geq 2 \mathrm{~mm}$-es, „vitorlaszerú”, „coved” ST-eleváció) a praecordialis elvezetésekben. Bemutatjuk a klinikai képet és lefolyást, valamint ismertetjük a felmerülő differenciáldiagnosztikai problémákat és az EKG-elváltozások lehetséges okait. Orv. Hetil., 2016, 157(50), 2007-2010.
\end{abstract}

Kulcsszavak: elektrokardiográfia, alsó fali myocardialis infarctus, Brugada-EKG-mintázat, feszülő pneumothorax, differenciáldiagnózis

\section{A rare ECG manifestation of left sided pneumothorax: inferior STEMI with precordial Brugada pattern}

\begin{abstract}
Recognition and identification of the cause of non-coronary ST elevation is important in daily practice, mainly for avoiding unnecessary diagnostic and therapeutic procedures. In this case, a rare cause, spontaneous, left sided tension pneumothorax was in the background of the suddenly appearing, complex ECG changes - ST elevation mimicking inferior wall myocardial infarction associated with type 1 Brugada pattern ("coved" ST-segment elevation $\geq 2 \mathrm{~mm}$ ) in the precordial leads. The clinical picture and course, the differential diagnostic problems related to the case and the possible causes of the ECG changes will be presented.
\end{abstract}

Keywords: electrocardiography, inferior wall myocardial infarction, Brugada ECG pattern, tension pneumothorax, differential diagnosis

Frigy, A., Kocsis, I., Fehérvári, L., Máthé, L. [A rare ECG manifestation of left sided pneumothorax: inferior STEMI with precordial Brugada pattern]. Orv. Hetil., 2016, 157(50), 2007-2010.

(Beérkezett: 2016. szeptember 16.; elfogadva: 2016. október 16.)

\section{Rövidítések}

$\mathrm{BrSz}=$ Brugada-szindróma; NCESTE = nem coronariás eredetû ST-eleváció

Az akutan megjelenő ST-eleváció rendszerint a súlyos, transmuralis myocardialis ischaemia EKG-megnyilvánulása, myocardialis infarctusra, vasospasticus anginára jel- lemző. Az akut vagy krónikus ST-elevációnak ugyanakkor számos egyéb, nem coronariás oka is lehet. Elsősorban a felesleges diagnosztikus és terápiás eljárások elkerülése érdekében fontos a mindennapi gyakorlatban ezeknek az EKG-elváltozásoknak a helyes értelmezése, etiológiai diagnózisa. A nem coronariás eredetű ST-eleváció (NCESTE) legfontosabb okait az 1. táblázatban tüntettük fel [l-3]. 
1. táblázat | Nem coronariás eredetű ST-elevációk okai

\begin{tabular}{ll}
\hline Primer repolarizációs zavar & Szekunder repolarizációs zavar \\
\hline Brugada-szindróma & Szárblokk \\
Korai repolarizáció & WPW-szindróma \\
$\begin{array}{l}\text { Pericarditis/myocarditis } \\
\text { Hyperkalaemia }\end{array}$ & Balkamra-hypertrophia \\
Hypercalcaemia & Akut jobbkamra-túlterhelés \\
Áramütés/DC-sokk & (tüdóembólia) \\
Cerebralis (vérzés, trauma, & Bal kamrai (csúcsi) aneurysma \\
ödéma) & \\
\hline Egyéb & \\
\hline Normális variáns & \\
Mútermék & \\
\hline
\end{tabular}

Az NCESTE egyik sajátos variánsa a Brugada-EKGmintázat, amely a Brugada-szindróma $(\mathrm{BrSz})$ velejárója. Ez egy genetikailag meghatározott, úgynevezett primer elektromos szívbetegség (ioncsatorna-betegség), amelyre jellegzetes EKG-mintázat, illetve a hirtelen szívhalál előfordulásának fokozott rizikója jellemző [4]. A BrSz-t számos gén mutációja okozhatja, amelyek következménye a befelé irányuló depolarizáló áramok $\left(\mathrm{I}_{\mathrm{Na}}\right.$ és $\left.\mathrm{I}_{\mathrm{Ca}}\right)$ erôsségének csökkenése, illetve a kifelé irányuló, repolarizáló áramok (például $\mathrm{I}_{\mathrm{to}}, \mathrm{I}_{\mathrm{K}-\mathrm{ATP}}$ ) intenzitásának fokozódása [5]. Az EKG-elváltozás és a malignus kamrai aritmiák elsődleges elektrofiziológiai alapja a repolarizáció transmuralis inhomogenitása, amely 2 -es fázis típusú reentryt indít be, következményes kamrai ectopiával, illetve polimorf kamrai tachycardiával és kamrafibrillációval [6].

Az entitás EKG-osztályozási szempontból az úgynevezett J-hullám-szindrómák csoportjába tartozik a korai repolarizációval együtt [7]. Patognomikus az l-es típusú Brugada-EKG-mintázat, amelynek lényege egy $\geq 2 \mathrm{~mm}$ es deszcendáló, „vitorlaszerű” [8], „coved” ST-eleváció, amely legalább egy jobb oldali mellkasi elvezetésben jelen van [9].
A BrSz-hez kapcsolódóan a klinikai gyakorlat szempontjából fontos az úgynevezett Brugada-fenokópiák ismerete és azonosítása. Ezek olyan, rendszerint tranzitórikus és akut klinikai állapotok, amelyek jellegzetes l-es típusú Brugada-EKG-mintázattal járnak $[10,11]$.

A továbbiakban ismertetjük egy komplex NCESTE-t mutató esetünket, akinél az EKG-elváltozások hátterében egy viszonylag ritka ok állt.

\section{Esetleírás}

A 62 éves férfi beteget a mellkassebészeti osztályról helyezték át klinikánkra mütét előtti állapotfelmérés, előkészítés céljából. Pulmonalis alapbetegsége jobb oldali tüdőtumor, krónikus obstruktív tüdőbetegség volt, negatív kardiális anamnézissel és közepesen leromlott fizikális állapottal társulva.

Egy órával a kórterembe érkezését követően a beteg állapota hirtelen válságosra fordult, súlyos nehézlégzés, bal oldali, erôs, szorító-szúró jellegú mellkasi fájdalom, ájulásérzés megjelenésével.

Fizikális vizsgálattal cyanosis, sápadt és hideg végtagok, filiformis, irreguláris pulzus, halk, szabálytalan és tachycardiás szívhangok voltak tapasztalhatók. A vérnyomás 90/60 Hgmm volt, míg a mellkas fizikális vizsgálatával a bal oldalon hiányzó alaplégzést és tympanismust lehetett észlelni.

A rögzített EKG-görbén (1. ábra) gyors kamrai frekvenciájú pitvarfibrilláció, hiányzó R-hullám-progresszió a mellkasi elvezetésekben, jobbra forgatott QRS-tengely, valamint diffúz ST-eleváció (a lateralis elvezetések kivételével) volt látható. A jobb oldali praecordialis elvezetésekben jellegzetes, kifejezett l-es típusú Brugada-mintázat jelent meg, míg az alsó fali elvezetésekben akut infarktusra jellemző ST-eleváció alakult ki.

A technikailag meglehetősen nehezen kivitelezhető (epigastrialis ablakból) szív-ultrahangvizsgálat során nor-

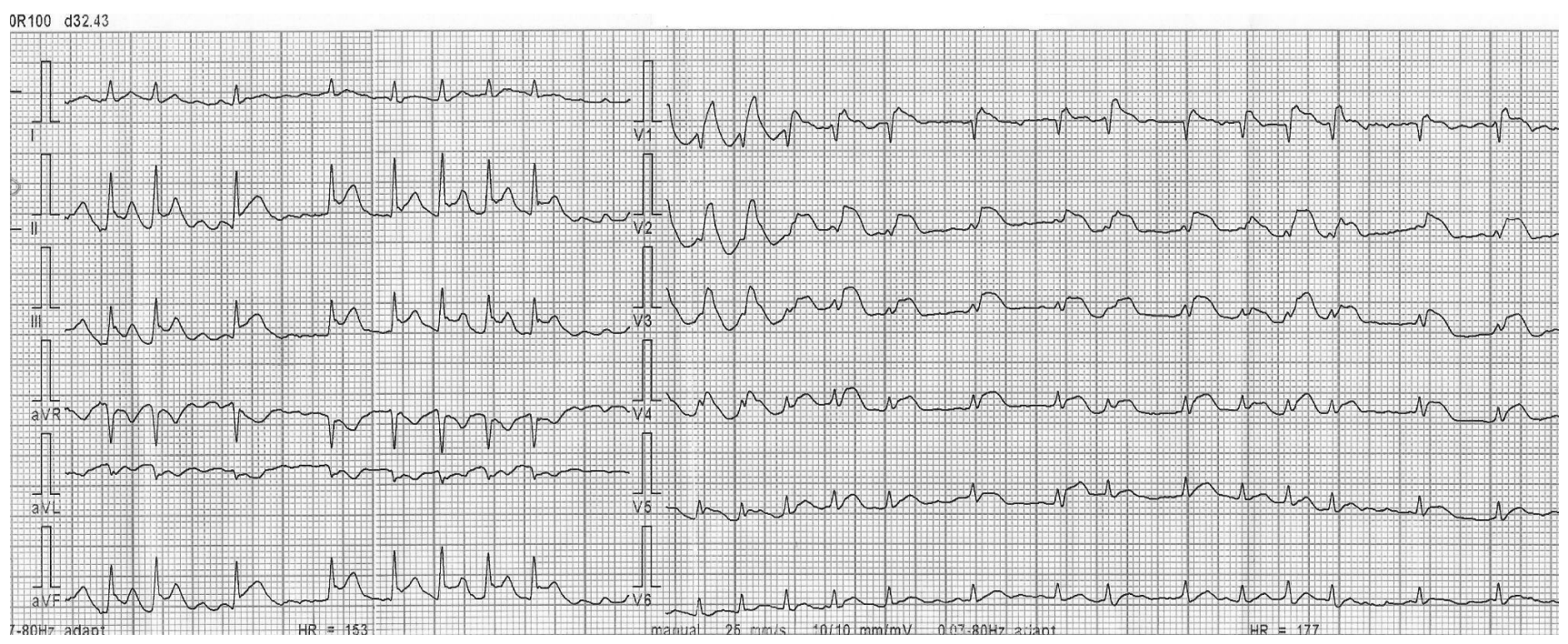

1. ábra

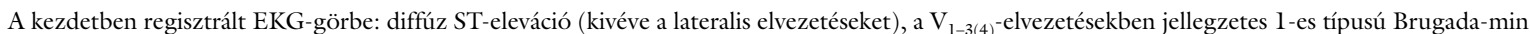
tázattal, az alsó fali elvezetésekben STEMI-nek megfelelő aspektussal 
mális tágasságú, hiperkontraktilis bal kamrát találtunk. Szegmentális falmozgászavar, jobb kamrai túlterhelés és pericardialis gyülem nem volt látható, az aortagyök normális tágasságú volt.

A fizikális vizsgálat, valamint a kritikus hemodinamikai állapot által felvetett feszülő pneumothorax gyanúját az elvégzett sürgőségi mellkasi CT-vizsgálat igazolta (2. ábra).

Az azonnal elvégzett mellkaspunkciót, majd a folyamatos drénezést követően a beteg állapota drámaian javult, EKG-görbéje normalizálódott, diszkrét „memória”-Jhullámok fennmaradásával az inferolateralis elvezetésekben (3. ábra). A későbbiekben a beteg nem került újból osztályunkra, ugyanakkor az eredetileg tervezett mútétet a fellépett szövődmény miatt nem végezték el.

\section{Megbeszélés}

Betegünk esetében a tünetek, a hemodinamikai státusz (cardiovascularis kollapszus), valamint az EKG-n látható domináns elváltozás (kiterjedt ST-eleváció) alapján a kezdeti, lehetséges (munka)diagnózisok a következők voltak: kiterjedt STEMI, akut pericarditis tamponáddal, masszív tüdőembólia, bal oldali feszülő légmell.

A fizikális vizsgálat során igazolódott a pneumothorax, ugyanakkor a szívultrahang gyakorlatilag kizárta a

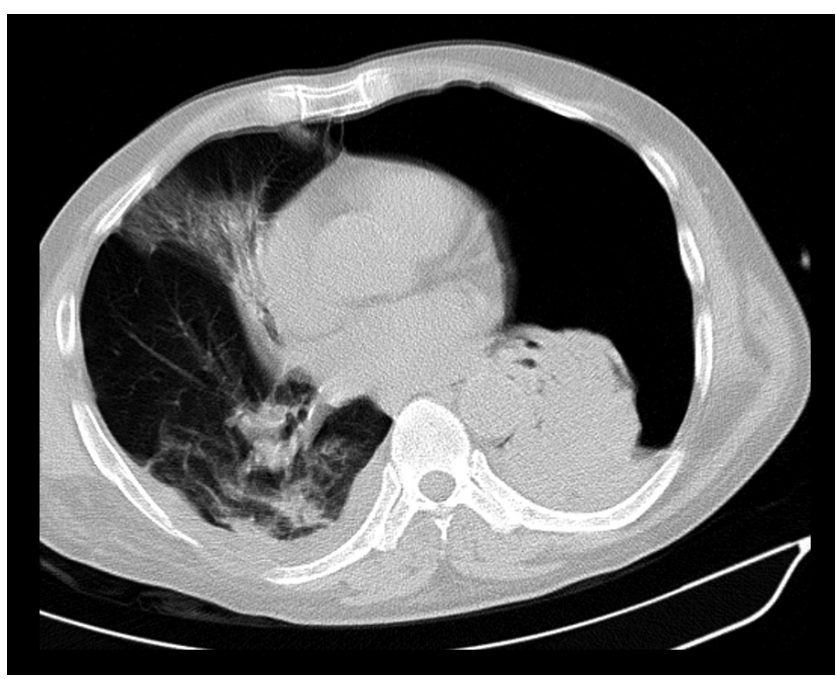

2. ábra $\mid$ Mellkasi CT-felvétel: kiterjedt bal oldali, feszülő pneumothorax a szív és a mediastinum diszlokációjával, parenchymás laesiók a jobb tüdőben

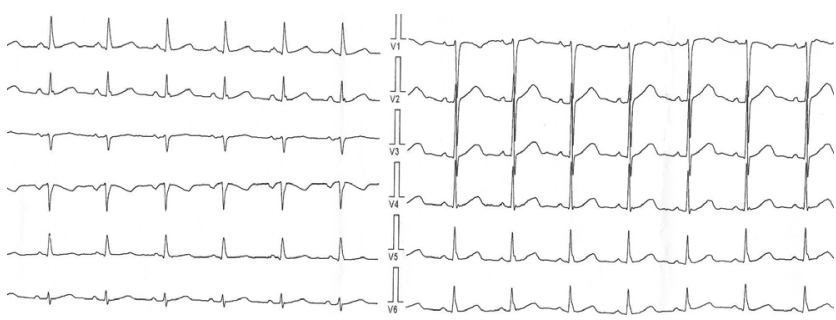

3. ábra

Az EKG-görbe normalizálódása a mellkasi drén behelyezését követően. Diszkrét „memória”-J-hullámok az inferolateralis elvezetésekben többi diagnózist (falmozgászavar, pericardialis gyülem és a jobb kamrai túlterhelés hiánya). A végleges kórismét a sürgősségi mellkas-CT állította fel.

A kezdetben regisztrált EKG-görbe fó jellegzetessége egy komplex ST-eleváció, amely $\mathrm{V}_{1-3}$-ban egyértelmü 1-es típusú Brugada-EKG-mintázatot mutatott, míg az alsó fali elvezetésekben akut STEMI-re jellemzőt.

Az irodalomban csak néhány közlemény foglalkozik EKG-elváltozásokkal pneumothorax esetén, és egyikben sem történik említés az általunk talált EKG-mintázatról. A hasonló EKG-görbét mutató betegeknek jobb oldali pneumothoraxa volt, ami jelzi, hogy az elváltozások kialakulásában az oldaliságnak valószínúleg nincs szerepe [12-14].

A korábbi megfigyelésekre és adatokra támaszkodva, esetünkben az EKG-elváltozások lehetséges magyarázata meglehetősen komplex, több mechanizmust is magába foglal: 1. a szív, elsősorban a jobb kamrai kiáramlási pálya mechanikai irritációja a külső kompresszió révén; 2. a szív diszlokációja, valamint rotációja a hossztengelye körül; 3. jobb kamrai túlterhelés a megnövekedett pulmonalis rezisztencia miatt; 4 . ischaemia, a coronariakompresszió, hypoxaemia, gyors pitvarfibrilláció és hypotensio miatt; 5. vegetatív hatások [15-17].

Pneumothorax mellett ritkán előfordulhat az úgynevezett „spiked helmet” ST-eleváció is, amely az NCESTE egy másik sajátos mintázata $[18,19]$.

\section{Következtetés}

A bemutatott eset sajátossága annak elektrokardiográfiai ritkaságában áll - 1-es típusú Brugada-EKG-mintázat megjelenése spontán fellépő bal oldali feszülő pneumothoraxban, illetve a Brugada-mintázat társulása alsó fali akut infarktusra jellemző ST-elevációval, ugyanazon az EKG-görbén. Klinikai jelentőségét az adja, hogy az EKG önmagában történő értékelése késleltetheti a helyes diagnózis megtalálását és az adekvát kezelés elvégzését. Ezért nem lehet elégszer hangsúlyozni, hogy az EKG egy nagyon fontos, könnyen elvégezhető, „ágy melletti” vizsgálat, de sok helytelen, félrevezető diagnózis születhet, ha nem tesszük mellé a beteg klinikumát.

Anyagi támogatás: A közlemény megírása, illetve a kutatómunka anyagi támogatásban nem részesült.

Szerzôi munkamegosztás: F. A.: A beteg klinikai követése, az adatok és leletek dokumentálása, a kézirat megszövegezése. K. I., F. L.: A beteg klinikai követése, ellátása, az adatok és leletek dokumentálása. M. L.: Az adatok és leletek dokumentálása, a kézirat megszövegezése. A cikk végleges változatát valamennyi szerző elolvasta és jóváhagyta.

Érdekeltségek: A szerzőknek nincsenek érdekeltségeik. 


\section{Köszönetnyilvánítás}

Köszönettel tartozunk Prof. Dr. Tomcsányi Jánosnak a kézirat elkészítéséhez adott tanácsaiért.

\section{Irodalom}

[1] Wang, K., Asinger, R. W., Marriott, H. J.: ST-segment elevation in conditions other than acute myocardial infarction. N. Engl. J. Med., 2003, 349(22), 2128-2135.

[2] Hanna, E. B., Glancy, D. L.: ST-segment elevation: differential diagnosis, caveats. Cleve. Clin. J. Med., 2015, 82(6), 373-384.

[3] Deshpande, A., Birnbaum, Y.: ST-segment elevation: distinguish ing ST elevation myocardial infarction from ST elevation secondary to nonischemic etiologies. World J. Cardiol., 2014, 6(10), 1067-1079.

[4] Brugada, P., Brugada, J.: Right bundle branch block, persistent ST segment elevation and sudden cardiac death: a distinct clinical and electrocardiographic syndrome. A multicenter report. J. Am. Coll. Cardiol., 1992, 20(6), 1391-1396.

[5] Campuzano, O., Sarquella-Brugada, G., Brugada, R., et al.: Genetics of channelopathies associated with sudden cardiac death Glob. Cardiol. Sci. Pract., 2015, 2015(3), 39.

[6] Bébarová, M.: Arrhythmogenesis in Brugada syndrome: impact and constrains of current concepts. Int. J. Cardiol., 2013, $167(5), 1760-1771$.

[7] Antzelevitch, C., Yan, G. X.: J-wave syndromes: Brugada and early repolarization syndromes. Heart Rhythm., 2015, 12(8), 1852-1866.

[8] Tomcsányi, J.: Brugada syndrome and Brugada phenocopy. [Brugada-szindróma és Brugada-fenokópia. In: EKG a sürgősségi betegellátásban. 2 . kiadás. Use electrocardiogram in urgent medical attendance. Ed.: Tomcsányi, J.] Tordas és Társa, Budapest, 2016, 125-136.

[9] Bayés de Luna, A., Brugada, J., Baranchuk, A., et al.: Current electrocardiographic criteria for diagnosis of Brugada pattern: a consensus report. J. Electrocardiol., 2012, 45(5), 433-442.
[10] Anselm, D. D., Evans, J. M., Baranchuk, A.: Brugada phenocopy: A new electrocardiogram phenomenon. World J. Cardiol., 2014, $6(3), 81-86$.

[11] Tomcsányi, J.: Brugada phenocopy. [Brugada-fenokópia.] Orv. Hetil., 2016, 157(13), 495-499. [Hungarian]

[12] Shiyovich, A., Vladimir, Z., Nesher, L.: Left spontaneous pneumothorax presenting with ST-segment elevations: A case report and review of the literature. Heart Lung, 2011, 40(1), 88-91.

[13] Anderson, R., Costello, B., Kilpatrick, D.: Transient ST-segment elevation resembling acute myocardial infarction in a patient with a right secondary spontaneous pneumothorax. Heart Lung Circ., 2013, 22(2), 149-152.

[14] Janssens, U., Koch, K. C., Graf, J., et al.: Severe transmyocardial ischemia in a patient with tension pneumothorax. Crit. Care Med., 2000, 28(5), 1638-1641.

[15] Saks, M. A., Griswold-Theodorson, S., Shinaishin, F., et al.: Subacute tension hemopneumothorax with novel electrocardiogram findings. West. J. Emerg. Med., 2010, 11(1), 86-89.

[16] Krenke, R., Nasilowski, J., Przybylowski, T., et al.: Electrocardiographic changes in patients with spontaneous pneumothorax. J. Physiol. Pharmacol., 2008, 59(Suppl. 6), 361-373.

[17] Price, J. W.: Novel electrocardiographic changes associated with iatrogenic pneumothorax. Am. J. Crit. Care, 2006, 15(4), 415419.

[18] Littmann, L., Monroe, M. H.: The "spiked helmet" sign: a new electrocardiographic marker of critical illness and high risk of death. Mayo Clin. Proc., 2011, 86(12), 1245-1246.

[19] Tomcsányi, J., Arabadzisz, H., Bózsik, B.: The etiology of ST-segment elevation. J. Electrocardiol., 2008, 41(6), 696

(Frigy Attila dr., UMF Tg. Mureș, Internal Medicine IV, Gh. Marinescu str. 1 540400 Târgu Mureş, Romania e-mail: afrigy68@gmail.com)

\section{Az Orvosi Hetilap 2016, 157, 1816. oldalán (45. szám) OH-Kvízre egy helyes megfejtés érkezett.}

A beküldő: Dr. Bíró László.

A nyertesnek szívböl gratulálunk.

Nyereményét - egy, az Akadémiai Kiadó webáruházában kedvezményes vásárlásra jogosító kupont - e-mailen küldjük el. 